\section{Setting up in practice}

\author{
M. Cock*
} In a world where everything in dentistry seems to be rapidly
changing it is perhaps surprising just how many younger
dentists maintain an image of a 'perfect', and quite traditional,
career path, from VDP to associate to practice owner.

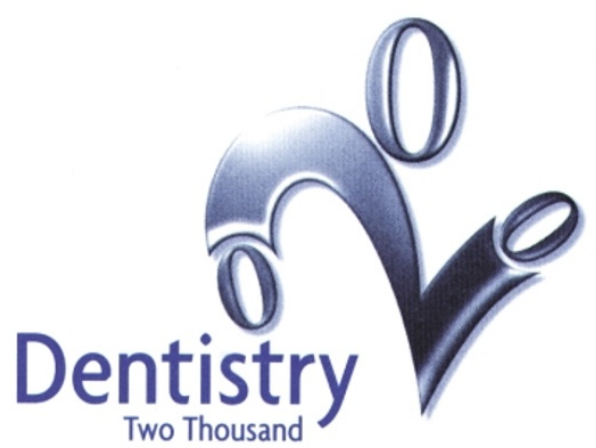

While specialisation, the growth of the corporate bodies, re-certification and continuing postgraduate education quite rightly grab the headlines in the dental press, many recent (and quite a few not-so-recent) graduates maintain a dream of 'a practice of my own', with their own personal stamp on everything from the stationery to the staff.

For many, the 'dream' remains just that. Others take the plunge without more than a second thought or visit to the bank manager. But for most, the opportunity to seriously weigh up all the issues, listen to the experiences of some successful practice owners, and exchange views with their peers, is absolutely invaluable.

When the BDA first piloted a course at Wimpole Street called 'Setting up in Practice' back in 1997, it sent out a few hundred letters to dentists in the London area who'd graduated in the previous ten years. Within a month, we had received payments from 100 delegates, the Lecture Theatre was full and we had a waiting list!

Since then, the course has been refined and further developed and run a further six times — in Birmingham, Leeds, Manchester and Torquay as well as London - filling up and selling out nearly every time.

The basic format, however, has remained the same: An overview from Raj Rattan; a speaker on business plans; sessions on the two options of 'setting up from scratch' and 'buying into an existing practice'; an overview of employment law; and a whistlestop tour of the current dento-legal scene.

Raj Rattan established his first practice in Oxford in 1982 and runs another in London. Also heavily involved in dental education, as a VT adviser and former DGDP examiner, a Health Authority adviser and dento-legal

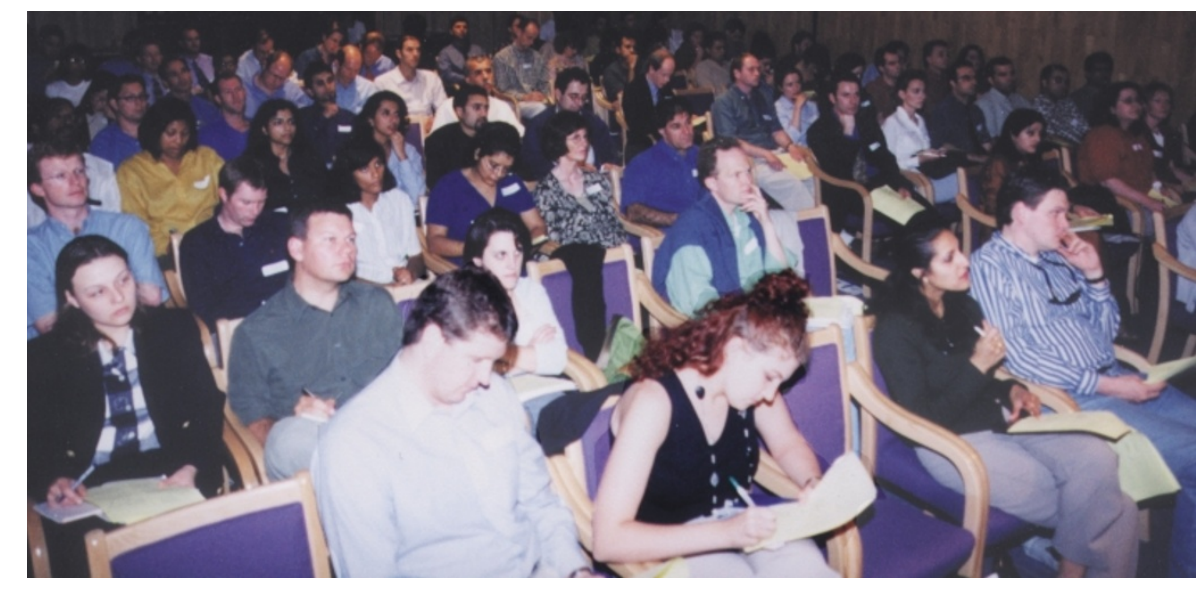

Delegates at a 'Setting up in practice' seminar last year. adviser for Dental Protection, Raj's 'Your Next Step?' presentation always goes down well with those who are unsure whether starting up in practice is for them.

While the talk is all about new brands and concepts, the basic options open to dentists setting out on their own remain timeless. You either set up from scratch, take over a former shop, equip a surgery and hope/pray for the patients to start arriving — or you buy into the practice you are working in or search the $B D J$ advertisements for something better.

So the BDA's course covers both of these options in some detail. Steve Byfield, who always advertises himself as a 'wet fingered' and 'average' (whatever that may mean) dentist from North Yorkshire has some important and very practical advice for those who want to buy into an existing practice. Raj, again, covers the prospects for those starting from scratch, including invaluable advice on marketing and practice promotion.

For readers for whom the purchase of their own practice is long behind them, the other
The next 'Setting up in Practice' course is at 9.30am on Friday 7th April as part of Dentistry 2000 in Birmingham. The course also runs on Saturday 24th June at the BDA Headquarters, London.

Prices (including lunch) are $£ 55$ for BDA members, $£ 75$ for nonmembers, and $\mathbf{£ 6 5}$ for non-dentist partners. For further details contact the Young Dentist office at the BDA, phone 02079350875 (ext 260). thing that has not really changed is that you need money! Nowadays, though, you are expected to come up with a proper business subjects that remain a mystery to most dentists. The course's session on business planning always has the audience scribbling away furiously.

What has changed undeniably is that employment law is much more complex than it used to be. Get the right staff and your dream practice runs like a dream. Get it wrong and it could become a nightmare of complaints, lost patients and even litigation. Again, most associates have very little idea of this area of legislation. Tracy Winter, the BDA's in-house barrister, is always much in demand for individual advice following her session at the course.

Similarly, health and safety legislation have become minefields for the unwary practitioner. Lesley Chartres, the BDA's health and safety expert and Bryan Harvey, Deputy Head of the Dental Defence Union, offer helpful sessions on these subjects.

It may be that, in the future, a course on 'Setting up in Practice' will seem as antiquated and quaint as some of the exhibits in the BDA's library. Then again, probably not.

\footnotetext{
* Martin Cock, Recruitment and Marketing
} Manager, BDA. plan, cash flow projections and so on - 